7. Reprod. Fert. (1967) 13, 75-82

\title{
THE EFFECT OF PROGESTERONE ON SERUM LUTEINIZING HORMONE CONCENTRATIONS IN THE EWE
}

\author{
P. G. MaDONALD* AND M. T. GLEGG \\ Department of Animal Husbandry, University of California, \\ Davis, California \\ (Received 10th Fanuary 1966)
}

\begin{abstract}
Summary. Circulating levels of $\mathrm{LH}$ have been determined in intact and ovariectomized ewes before, during and after progesterone treatment. Neither 20 nor $40 \mathrm{mg}$ progesterone daily for 10 days decreased the serum LH concentration during treatment. Following withdrawal, elevated levels of LH occurred on Days 4 to 6 in both intact non-cycling and ovariectomized ewes. Intact ewes treated during the initiation of the breeding season showed depressed levels of $\mathrm{LH}$ and failed to respond to progesterone treatment. The injection of $40 \mathrm{mg}$ of progesterone daily did not delay the time of occurrence of the peak in LH activity.
\end{abstract}

\section{INTRODUCTION}

The effect of progesterone administration on pituitary gonadotrophin secretion and release has been investigated by numerous workers. However, many of these studies have yielded inconsistent results. Greep \& Chester-Jones (1950) were not able to detect any changes in total pituitary gonadotrophin content of intact female rats treated with $1 \mathrm{mg}$ of progesterone daily for 45 days. However, Byrnes, Meyer \& Finnerty (1951) noted a decrease in total blood gonadotrophin levels in parabiotic rats whose partners received from 0.5 to 1.0 $\mathrm{mg}$ of progesterone daily for 10 days. More recently McCann (1962) found that one or two injections of $25 \mathrm{mg}$ of progesterone into ovariectomized female rats resulted in a decline in plasma LH concentration 2 days later.

The urinary gonadotrophin data of Smith \& Albert (1956) and Rothchild (1957) are likewise conflicting. Three different groups of workers, Nellor \& Cole (1957), Ray, Emerson \& Melampy (1961) and Labhsetwar, Tyler, Meyer \& Casida (1964) have reported no effect, a decrease and increase respectively in the pituitary concentration of gonadotrophin in progesterone-treated heifers.

To date, the majority of workers have taken samples 1 to 3 days after the cessation of progesterone treatment. In addition, few experiments have been

\footnotetext{
* Present address: Department of Anatomy, School of Medicine, University of California, Los Angeles, California.
} 
carried out in which the gonadotrophin levels have been determined both during and after progesterone treatment. Finally, only a few workers have used specific and quantitative bio-assays to evaluate the levels of LH and FSH present in the blood and pituitary.

On the basis of some recent observations (Ellington, Contopoulos \& Clegg, 1964 ; Hoffman \& Schwartz, 1965) it is possible to formulate a possible mechanism of action for progesterone; namely that the presence of the hormone itself does not bring about any major changes in gonadotrophic activity, rather it is the alteration in progesterone titres at the start and end of treatment that are responsible for gonadotrophin release. The purpose of this investigation was to test this action of progesterone using a specific and quantitative bio-assay for LH in the blood of the ewe during and following a regimen of progesterone injections. The results of this work have appeared previously in abstract form (McDonald \& Clegg, 1965).

\section{MATERIALS AND METHODS}

Ten intact and twenty ovariectomized ewes of mixed fine wool breeding were used in a series of four separate experiments. Progesterone was administered daily for 10 days at a level of $20 \mathrm{mg} /$ day in the first three experiments and 20 or $40 \mathrm{mg} /$ day in Experiment 4. Blood was collected from the cavernous sinus of the unanaesthetized ewe by the technique of McFarland, Clegg \& Ganong (1960). On those days on which progesterone was administered blood was collected immediately before the intramuscular injection of the hormone. Following collection, the blood was allowed to clot at $4^{\circ} \mathrm{C}$, centrifuged at 6000 to $8000 \mathrm{rev} / \mathrm{min}$ for 10 to $15 \mathrm{~min}$ at $0^{\circ} \mathrm{C}$ and stored in the freezer until assayed.

LH was determined by the ovarian ascorbic acid depletion (OAAD) technique of Parlow (1961). Immature female rats of the Sprague-Dawley strain, 22-daysold, were treated with 100 i.u. of PMS on Day 25 followed $65 \mathrm{hr}$ later by 50 i.u. of HCG. They were used for bio-assay 6 to 8 full days after the injection of HGG. A minimum of five rats/treatment group was used throughout. The test substance, $2 \mathrm{ml}$ whole sheep serum $/ 100 \mathrm{~g}$ body weight, was injected into the lateral tail vein of the lightly anaesthetized rat over a $45-$ to $60-\mathrm{sec}$ period. Four hours \pm 10 min later the left ovary only was removed and weighed on a torsion balance to the nearest $0.2 \mathrm{mg}$. Ovarian ascorbic acid was determined by the method of Mindlin \& Butler (1938) and expressed in terms of $\mathrm{mg} / 100 \mathrm{mg}$ ovary weight. In each assay two dose levels of NIH LH s-7 were included with a four-fold dose difference between the levels. The amounts of LH used were $0 \cdot 8$ and $3.2 \mu \mathrm{g} / 100 \mathrm{~g}$ body weight of the assay animal. The slope, standard deviation and index of precision of each assay was calculated according to the method of Bliss (1952).

\section{RESULTS}

The lower level of standard used in these analyses $(0.8 \mu \mathrm{g})$, was sufficiently above the MED of $0.4 \mu \mathrm{g}$ to insure significant depletions of ascorbic acid in $95 \%$ or more of the assays. The indices of precision $(\lambda)$ were, in all cases, satisfactory 
being well below the upper limit of 0.3 (0.167 for twenty-nine assays). In addition, the mean $\mathrm{mg} / 100 \mathrm{ml}$ ovarian ascorbic acid values in saline-treated rats remained fairly stable over the 10 -month period during which the assays were carried out (range $93.5 \mathrm{mg} / 100 \mathrm{ml}$ to $97.4 \mathrm{mg} / 100 \mathrm{ml}$ ).

The serum LH concentration in intact ewes treated with $20 \mathrm{mg}$ of progesterone daily during the late anoestrous period is shown by the open bars in Text-fig. 1 . In this experiment all blood samples collected on any one day were assayed at one time. All ten ewes were sampled on Days 0,5 and 15 and five animals on each of the remaining days. The datum is thus a good indication of the variation between individual ewes on each day. The levels of LH did not appear to be significantly depressed during progesterone treatment. However, following progesterone withdrawal elevated levels of $\mathrm{LH}_{\mathrm{H}}$ were seen on Day 15. The large

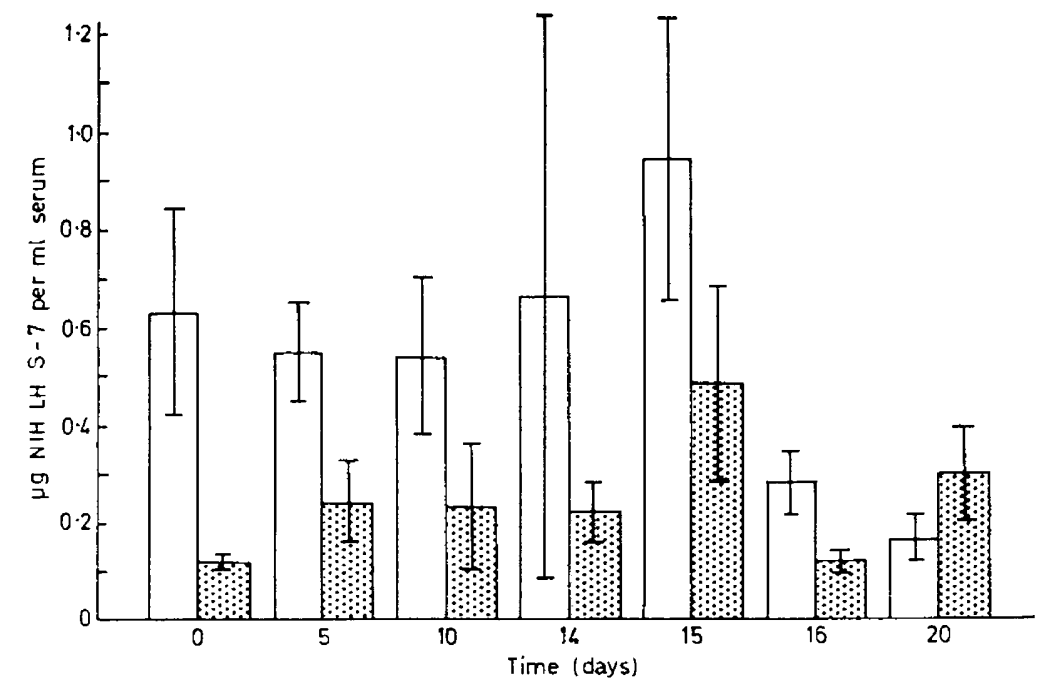

TexT-FIG. 1. Comparison of the serum LH activity between intact ewes treated with $20 \mathrm{mg}$ of progesterone daily during the non-breeding and early breeding season. The bars and vertical lines represent means and standard errors. In Experiment 1 (unshaded columns), ten ewes were sampled on Days 0,5 and 15, five ewes on Days 10,16 and 20 and four ewes on Day 14. In Experiment 3 (stippled column), seven ewes were sampled on each day.

standard error on Day 14 was due to one ewe which showed a peak of LH concentration on this day, while the level in the three remaining ewes did not change. Following the peak on Day 15 there was a sharp decline in LH concentration.

Text-fig. 2 (Expt. 2) shows the data obtained from a group of ovariectomized ewes treated in a similar manner. During the injection of progesterone, the serum LH concentration was slightly lower compared to control (Day 0) values though the control level was slightly, but not significantly, lower than that for the intact animals. As in Expt. 1, a peak in serum LH concentration was noted on Day 15 or 5 days after the withdrawal of progesterone. Although this response was similar to that in the intact ewes the elevated levels persisted over a longer period of time. In addition the fall in LH concentration following 
the peak was not as marked in the ovariectomized animals as in the intact ones.

The third experiment (black bars; Text-fig. 1) was carried out during the onset of cyclic activity and involved the intact animals used in Expt. 1. In this instance all the samples collected from each individual ewe were assayed at one time. This gave a better indication of the day to day variation within each animal and, in addition, eliminated any differences occurring between assays. With the exception of Day 16 all samples collected during and after progesterone treatment had a greater activity than the non-treated control sample. Although there was an elevation in concentration on Day 15, it was not comparable to that obtained in Expt. 1. Of the seven ewes sampled on Day 15, only one animal showed an LH activity within the range found in the first experiment.

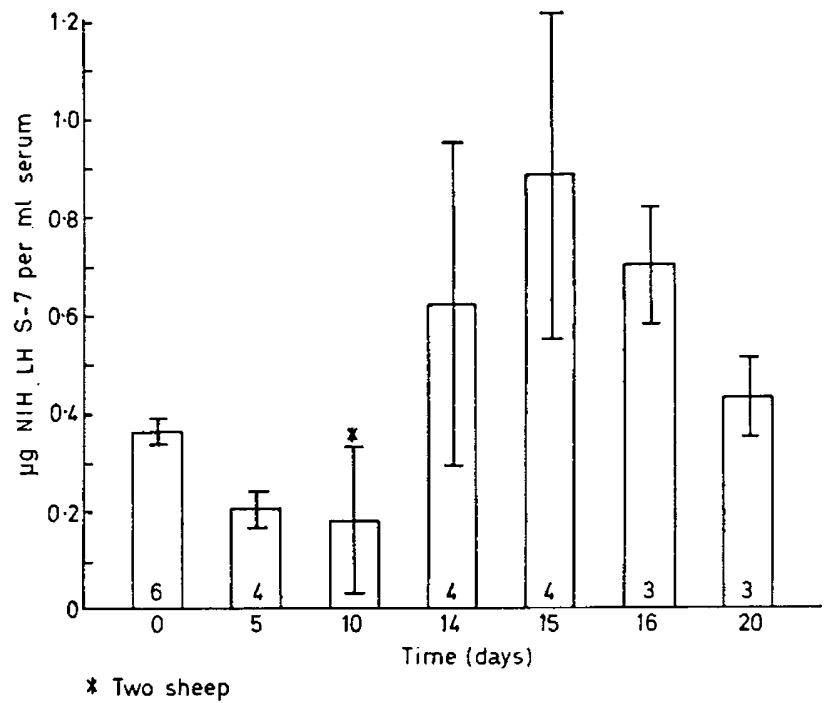

TEXT-FIG. 2. Serum LH activity in terms of NIH LH s-7 in ovariectomized ewes treated with $20 \mathrm{mg}$ of progesterone daily for 10 days. The bars and vertical lines represent means and standard errors. The number of ewes sampled is shown at the base of each column.

It was concluded that these ewes did not respond to progesterone withdrawal as was the case during the anoestrous period.

A comparison of the LH values found in Expts. 1 and 3 (Text-fig. 1) clearly shows that with the exception of Day 20, the serum concentration of $\mathrm{LH}$ is lower during the period when breeding activity normally starts than during the anoestrous season. Many of the values obtained were at the lower limit of the sensitivity of the assay and as such the quantitative estimates of the $\mathbf{L H}$ concentration may not be very accurate.

In the final experiment, two groups each of two ovariectomized ewes were treated with either 20 or $40 \mathrm{mg}$ of progesterone daily. The samples were assayed in a similar manner to those in Expt. 3 and the data obtained are shown in Text-fig. 3. Three of the four showed some depression of LH activity during progesterone treatment. Following progesterone withdrawal both the ewes receiving the $40 \mathrm{mg}$ level showed elevated serum LH titres, whereas only 
one of the ewes receiving the lower dose responded. The levels in one ewe receiving the high treatment dose remained elevated until Day 20. The individual values shown are typical of the variability which was noted between ewes. However, in this instance, some of the between-ewe variation can be attributed to the variability of the bio-assay from week to week.

Despite the small number of animals involved in this experiment, it would appear that higher levels of progesterone bring about a better response in terms of $\mathrm{LH}$ release. It is of interest that the peak levels occurred on the same day as in the previous experiments in which $20 \mathrm{mg}$ of progesterone were given. Thus, in these two ewes, increasing the level of progesterone did not delay the release of $\mathrm{LH}$ relative to cessation of treatment.

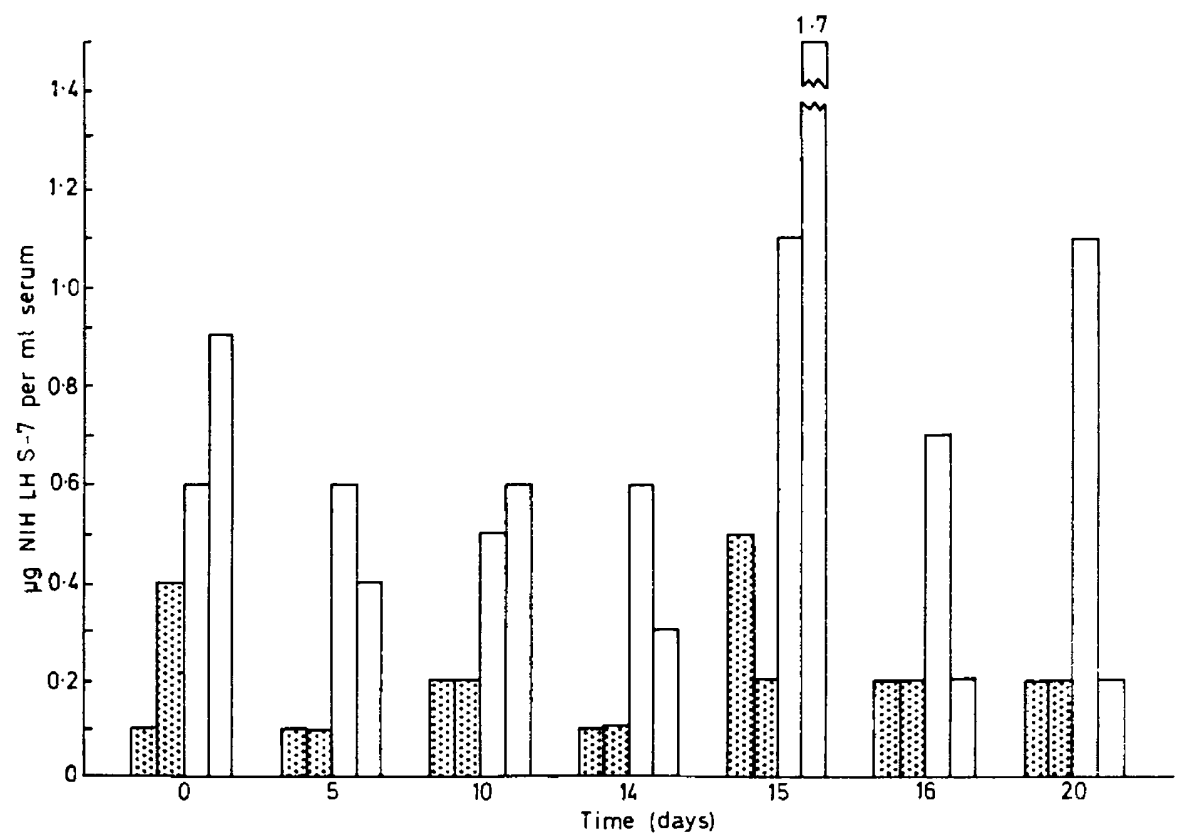

TeXT-FIG. 3. Serum LH activity in terms of NIH LH s-7 in ovariectomized ewes treated with either $20 \mathrm{mg}$ (stippled columns) or $40 \mathrm{mg}$ (unshaded columns) of progesterone daily. The four bars on each day represent the individual values for each ewe. Two ewes were used at each treatment level.

\section{DISCUSSION}

The determination of gonadotrophic activity in blood by the OAAD has been used to estimate levels in the rat (van Rees, 1959; Schwartz \& Caldarelli, 1965) and mouse (Parlow, 1964a). The data reported here indicate that the OAAD method is sufficiently sensitive, in most cases, to detect $\mathrm{LH}$ in $2 \mathrm{ml}$ of serum obtained from the cavernous sinus of the ewe. In the majority of samples, however, the LH concentration was towards the lower level of sensitivity of the assay. Such a problem might be overcome by using the 1-hr modification of the assay which has been shown to be several times as sensitive as the 4-hr test. Despite the large individual variations which occurred, the method, as used 
here, has proved of value in demonstrating major changes in LH concentration such as those occurring after progesterone withdrawal.

In general the injection of progesterone did not greatly affect the levels of $\mathbf{L H}$ in the serum during treatment. In view of the fact that gonadectomy in the sheep does not lead to an increase in serum LH concentration (McDonald \& Clegg, 1966), this result is not surprising. In contrast, the weak inhibitory effect of progesterone on the serum LH concentration in the ovariectomized rat (McCann, 1962) could be partly explained by the fact that following ovariectomy there is a rise in serum LH concentration (Parlow, 1964b). Thus, the administration of exogenous progesterone might be expected to have more effect in species in which the LH level increases following gonadectomy than in those species in which it remains constant. Although it has not been demonstrated, small doses of oestrogen in combination with progesterone could cause a reduction in serum LH levels in the sheep. Such a combination has been shown completely to inhibit LH secretion in the ovariectomized rat (McGann, 1962).

In regard to the elevations in serum LH concentration, no evidence could be found for an increase on the 5th day of progesterone treatment. This is in contrast to the data obtained by Ellington et al. (1964) in the wether. The reasons for this difference are not known at present; they may represent a specific sex difference in the response to progesterone or they could reflect the different assay procedures used in the two experiments.

The data collected following progesterone withdrawal are, with the exception of Expt. 3, in complete agreement with those found by Ellington et al. (1964). Although the increases are not large they are found consistently in both the intact and ovariectomized animals and occur at similar times in relation to the withdrawal of progesterone. In support of these data, recent work in the rat (Hoffman \& Schwartz, 1965) has shown that, following daily administration of progesterone for varying lengths of time, there is a sharp decrease in pituitary LH between 4 and 5 days after withdrawal in those cases in which ovulation was shown to have taken place. It is of interest that the temporal relationship in the two species is similar.

Although the major object of these experiments was not to determine ovulation as such, behavioural oestrus was checked daily in Expt. 3. However, only two ewes out of seven came into heat following progesterone withdrawal and neither of these showed any elevation in serum LH concentration. Since the ewes were not laparotomized no reliable estimate of the incidence of ovulation can be given.

The marked decrease in the serum LH levels of the intact ewes during the onset of cyclic activity can not be adequately interpreted at present. Other data (McDonald \& Clegg, 1966) indicate slightly but not significantly higher levels of LH during the anoestrous period as compared to mid-breeding season. In an earlier report, Kammlade, Welch, Nalbandov \& Norton (1952) noted a sharp drop in total pituitary gonadotrophin at first heat. Such a drop in pituitary content is characteristic of each oestrous cycle (Santolucito, Clegg \& Cole, 1960; Robertson \& Hutchinson, 1962) although the levels do not remain low throughout the whole cycle. 
Lamond (1964) has presented evidence to show that there is a dose response relationship between the level of progesterone and the time from withdrawal to oestrus and ovulation. To speculate on his findings, if the release of LH is in any way indicative of ovulation, then the ewes treated with $40 \mathrm{mg}$ of progesterone might have been expected to show a peak of $\mathbf{L H}$ activity somewhat later than the ewes receiving the $20-\mathrm{mg}$ dose. To confirm this hypothesis a larger group of animals is required.

The mechanism by which progesterone triggers the release of $\mathbf{L H}$ following a prolonged period of treatment is not known. The fact that this phenomenon occurs in the castrate male (Ellington et al., 1964) indicates that the effect is associated with the progesterone treatment and is not due to a synergism with other gonadal steroids. In the rabbit it has been shown that progesterone can both raise and lower arousal thresholds in the reticular formation of the brain (Kawakami \& Sawyer, 1959). This would suggest that progesterone can act, at least in part, through the central nervous system. It is possible that the declining level of progesterone results in a lowering of the neural thresholds concerned with the release of $\mathrm{LH}$.

\section{ACKNOWLEDGMENTS}

The authors wish to thank the Endocrinology Study Section of the National Institutes of Health for the generous supplies of NIH LH S-7. The pure crystalline progesterone used in this study was donated by the Syntex Corp., Inc. The technical assistance of Oscar Lang and Edith Nahas is gratefully acknowledged.

This study was supported in part by Grant No. B3977 from the United States Public Health Service.

\section{REFERENCES}

Burss, G. I. (1952) Statistics of bioassay. Academic Press, New York.

Byrnes, W. W., Meyer, R. K. \& Finnerty, J. C. (1951) Inhibition of gonadotropic hormones in female parabiotic rats by estrogen and progesterone. Am. F. Physiol. 164, 26.

Elinington, E. F., Contopoulos, A. N. \& CleGG, M. T. (1964) Progesterone regulation of the production and release of pituitary gonadotrophins in the gonadectomized sheep. Endocrinology, 75, 401.

Greep, R. O. \& Chester-Jones, I. (1950) Steroid control of pituitary function. Recent Prog. Horm. Res. $5,197$.

Hofpman, J. C. \& Schwartz, N. B. (1965) Timing of ovulation following progesterone withdrawal in the rat. Endocrinology, 76, 626.

Kammlade, W. G., Welch, J. A., Nalbandov, A. V. \& Norton, H. W. (1952) Pituitary activity of sheep in relation to the breeding season. 7. Anim. Sci. 11, 646.

KAWAKami, M. \& SAWYER, C. H. (1959) Neuroendocrine correlates of changes in brain activity thresholds by sex steroids and pituitary hormones. Endocrinology, 65, 652.

Labhsetwar, A. P., Tyler, W. J., MEYer, R. K. \& CASidA, L. E. (1964). Effect of gonadal hormones on the gonadotropic activity of the anterior pituitary gland of the spayed heifer. F. Anim. Sci. 23, 569 .

Lamond, D. R. (1964) Synchronization of ovarian cycles in sheep and cattle. Anim. Breed. Abstr. 32, 269.

McCann, S. M. (1962) Effects of progesterone on plasma luteinizing hormone activity. Am. J. Physiol. 202, 601 .

MaDonald, P. G. \& ClegGG, M. T. (1965) Effect of progesterone on serum LH levels in the ewe. $\mathcal{F}$. Anim. Sci. 24, 926.

McDonald, P. G. \& Clegg, M. T. (1966) Some factors affecting gonadotropin levels in sheep. Proc. Soc. exp. Biol. Med. 121, 482.

McFarland, L. Z., ClegG, M. T. \& Ganong, W. F. (1960) Concentration of ACTH in cavernous sinus and peripheral blood collected from unanaesthetized sheep. Proc. Soc. exp. Biol. Med. 103, 538. 
Mindlin, R. L. \& Butler, A. M. (1938) The determination of ascorbic acid in plasma; a macromethod and micromethod. 7. biol. Chem. 122, 673.

Nellor, J. E. \& Cole, H. H. (1957) The influence of exogenous progesterone on follicular development and pituitary hormone content of beef heifers. J. Anim. Sci. 16, 151.

Parlow, A. F. (1961) Bioassay of pituitary luteinizing hormone by the depletion of ovarian ascorbic acid. Human Pituitary Gonadotropins, p. 300. Ed. A. Albert. Charles C. Thomas, Springfield, Illinois.

Parlow, A. F. (1964a) Effect of ovariectomy on pituitary and serum gonadotrophins in the mouse. Endocrinology, 74, 102.

Parlow, A. F. (1964b) Comparison of pituitary and serum gonadotrophins of the rat. Endocrinology, 74, 489.

Ray, D. E., Emerson, M. A. \& Melampy, R. M. (1961) Effect of exogenous progesterone on reproductive activity in the beef heifer. 7 . Anim. Sci. 20, 373.

van Rees, G. P. (1959) The effect of progesterone on the ICSH and FsH content of anterior pituitary and blood. I. Survey of the literature; IcsH. Acta physiol. pharmac. néerl. 8, 195.

Robertson, H. A. \& Hutchinson, J. S. M. (1962) The levels of FSH and LH in the pituitary of the ewe in relation to follicular growth and ovulation. 7. Endocr. 24, 143.

RotнсніLd, I. (1957) Effect of large doses of intravenously administered progesterone on gonadotrophin excretion in the human female. 7. clin. Endocr. Metab. 17, 754.

Santolucito, J. A., Clegg, M. T.\& Cole, H.H. (1960) Pituitary gonadotrophins in the ewe at different stages of the estrous cycle. Endocrinology, 66, 273.

Schwartz, N. B. \& Caldarelli, D. (1965) Plasma lh in cyclic rats. Proc. Soc. exp. Biol. Med. 119, 16.

Smith, R. A. \& Albert, A. (1956) Effects of progesterone on urinary gonadotropin. Proc. Staff Meet. Mayo Clin. 31, 309. 